Second Language Processing in Japanese Scrambled Sentences

Sanako Mitsugi and Brian MacWhinney

Carnegie Mellon University

\begin{abstract}
Authors note
Sanako Mitsugi, Department of Modern Languages; Brian MacWhinney, Department of Psychology, Carnegie Mellon University.

Correspondence concerning this article should be addressed to Sanako Mitsugi, Department of Modern Languages, Carnegie Mellon University, 5000 Forbes Avenue, Pittsburgh, PA, 15213-3891. Phone: +1-412-268-4236. Fax: +1-412-2681328. Email: sanako@cmu.edu

This publication was made possible by the support of a CMU GuSH fund from the Graduate Student Assembly and the Graduate Support Programs Office. The authors would like to thank Bill VanPatten and Jill Jegerski as well as two anonymous reviewers for their insightful comments and suggestions on earlier version of this paper.
\end{abstract}




\begin{abstract}
This study used self-paced reading to examine the processing of Japanese ditransitive scrambling by native speakers and second language (L2) learners of Japanese. Because Japanese places the verb at the end of the clause, the impact of verb-based expectations should be less than it is in English (Trueswell, Tanenhaus \& Kello, 1993). Instead of using verb-driven processing, Japanese relies on case markers, and structure-building decisions are made locally (Miyamoto, 2002). As a result, if learners are able to utilize the information encoded by case markers, there should not be any extra processing load involved in scrambled sentences. Fifteen native speakers, 16 first language (L1) Korean intermediate-level learners, and 16 L1 English intermediate-level learners participated in the study. The conditions included canonical order, accusative scramble order, dative scramble order and dative-accusative scramble order. The results demonstrated that there are no significant differences in reading times among word-order types. These findings indicate that (1) Japanese native speakers make use of case-marked arguments as reliable cues for incremental processing, and (2) L2 learners can acquire this processing strategy at native-like levels, regardless of their L1 backgrounds.
\end{abstract}

Keywords: sentence processing, Japanese, ditransitive, case-markers 


\section{Second Language Processing in Japanese Scrambled Sentences}

Languages vary markedly in the degree to which they permit variable ordering of major sentence constituents. English involves fairly strict word-order constraints that provide crucial information for thematic role assignment. In the sentence, 'John gave Mary a book', the preverbal argument, 'John' is the Agent and the immediate postverbal argument 'Mary' is the Recipient. In the case of Japanese, on the other hand, grammatical relations are not encoded by word order, but by case marking on noun phases (NP). Save for the rule that verbs come at the end of sentences, case-marked NPs can be placed into alternative orders without changing the meaning of the sentence as shown in (1a) to (1f) ${ }^{1}$

(1) a. John-ga Mary-ni hon-o ageta

John-NOM Mary-DAT book-ACC give-PAST

'John gave Mary a book'

b. Mary-ni John-ga hon-o ageta

c. Hon-o John-ga Mary-ni ageta

d. Mary-ni hon-o John-ga ageta

e. Mary-ni hon-o John-ga ageta

f. Hon-o Mary-ni John-ga ageta

This licensing of word order variation is called scrambling (Ross, 1967). In the generative framework, scrambled sentences, such as (1b) to (1f), are more complex than their canonical counterpart, such as (1a) (Hoji, 1987). The additional complexity of the scrambled forms is expected to lead to an additional processing load during processing. Nevertheless, adult monolingual processing research has shown that, in Japanese, scrambled word order does not

\footnotetext{
${ }^{1} \mathrm{NOM}=$ nominative, $\mathrm{DAT}=$ dative, $\mathrm{ACC}=$ accusative case, $\mathrm{LOC}=$ locative, $\mathrm{DEC}=$ declarative , PAST $=$ Past tense, TOP $=$ Topic.
} 
necessarily result in processing difficulty. By utilizing the information encoded through case markers, Japanese comprehenders can process sentences incrementally without any delay (Miyamoto, 2002).

The ultimate goal for L2 learners is to learn to manage this rapid incremental use of case markers comprehension in a native-like fashion. Recently, a growing body of SLA research has investigated how learners go about processing L2 sentences online. This issue is of theoretical importance because it addresses the question of whether or not learners can acquire native-like processing strategies that that are different from those of their L1. Findings from L2 processing research also inform pedagogy. More specifically, they address what kinds of processing strategies L2 learners need to learn, and how to best configure optimal and effective language instruction.

Despite the wealth of findings that previous L2 processing studies have provided, studies on L2 sentence processing in Japanese are scarce. Nevertheless, the characteristics of Japanese processing such as case marker-driven incrementality offer a good testing ground for important psycholinguistic questions. The aim of the present study is to examine whether L2 learners process Japanese sentences incrementally utilizing the information from the case-marked NPs. The study includes two groups of L2 learners: learners whose L1 cue reliance either matches that of Japanese (L1Korean group) or does not (L1 English group). The syntactic structure under investigation is the Japanese ditransitive construction and associated scrambling configurations. In order to answer this question, we use a theoretical framework (MacWhinney, 2008) that emphasizes the role of cues and cue validity in sentence processing. 


\section{Background}

\section{Processing in Japanese}

The processing of head-final languages like Japanese is markedly different from the processing of languages like English. In English, lexical heads appear relatively early in sentences and provide early information for structural decisions. Head-driven parsing cannot apply in Japanese, because verbs are not available until the end of the sentence. These limitations become particularly crucial in the ditransitive structure, in which a verb holds three arguments in its thematic grid and these arguments can be subjected to both scrambling and omission.

From a generative viewpoint, the scrambled sentences are derived by a syntactic operation that applies to the canonical order as the base (Nemoto, 1999). Arguments are moved to the left of their base positions by adjoining an IP node to the top of the original IP and this process is called IP-adjunction (Saito, 1985). In the following sentences (1a) and (1b) are dstructure and s-structure representations of (2a) and (2b). The empty category position is shown by $t_{i}$ with co-reference of $i$.

(2) a. $\left[{ }_{I P}\right.$ John-ga $\left[{ }_{V P}\right.$ Mary-ni $\left[{ }_{V}\right.$, hon-o ageta $\left.]\right]$

b. $\left[{ }_{I P}\right.$ Mary-ni $\left[{ }_{I P}\right.$ John-ga $\left[{ }_{V P} t_{i}\left[{ }_{V}\right.\right.$, hon-o ageta $\left.\left.\left.]\right]\right]\right]$

In this perspective, scrambled sentences as in (1b), are syntactically more complex than their canonical counterparts in (1a). In the psycholinguistic literature, it is often argued that the additional complexity in scrambled word-orders should lead to an additional processing load, but many issues concerning scrambling in processing theory still remain controversial (Miyamoto, 2008). 
Scrambled sentences are fairly infrequent in Japanese. For monotransitives, Kuno (1973) found that canonically ordered sentences are 17 times more likely to occur than scrambled sentences in written text. More recently, Yamashita (2002) examined naturally occurring scrambled sentences and their surrounding contexts in various texts with different levels of formality. She found that there were only 19 instances of scrambling out of 2635 sentences. Miyamoto and Nakamura (2005) found that scrambled sentences are likely to involve higher ambiguity due to null arguments; in scrambled configurations it is rare for NP-ACC to be followed by explicit NP-NOM. In more than $98 \%$ of the scrambled instances, NP-NOM arguments were dropped and left implicit.

Despite their syntactic complexity, infrequent occurrence, and increased ambiguity, Japanese native speakers can process scrambled sentences as easily as their canonical counterparts. Previous studies have not found statistically reliable processing costs associated with scrambling in the ditransitive structure (Yamashita, 1997) and the monotransitive structure (Nakayama, 1995, but see Miyamoto \& Takahashi, 2002). Nakayama tested whether a trace of the scrambled object reactivates its antecedents in a probe recognition task. He found that the reaction times to the probes in the scrambled sentences were not significantly different from those in the canonical counterparts and interpreted the result as indicating that word-order variations do not necessarily create additional processing costs. Using self-paced reading, Yamashita investigated whether Japanese comprehenders rely on surface word-order or casemarking information with ditransitive constructions. Her results showed that there was no significant difference in reading times as a function of word-order types; Japanese native speakers processed scrambled sentences as readily as their canonical counterparts by keeping track of the information posed by case-markers without waiting for sentential final verbs. 
The manner in which Japanese monolingual adults process sentences incrementally contrasts markedly with findings for incremental processing in English, where verb information plays a significant role in determining expectations for possible continuations (MacDonald, Pearlmutter, \& Seidenberg, 1994; Trueswell, Tanenhaus, \& Kello, 1993). Instead, incremental processing in Japanese relies on the ways in which case-markers provide information for immediate role assignment (Miyamoto, 2002; Yamashita, 1997). Kamide, Altmann, and Haywood (2003) investigated how the information from pre-head arguments is utilized for anticipating what classes of argument to follow, with eye-tracking methodology. The claim, according to Kamide et al., is that, in the ditransitive construction, sentences beginning with a sequence of NP-NOM and NP-DAT signal that the third NP will be marked in the accusative case. Subsequently, the parser can anticipate an incoming verb that will denote an act of transference from Agent to Goal, in which an upcoming Theme will be whatever is transferrable. Kamide et al. demonstrated that the participants' eye-movement patterns show that Japanese comprehenders predict incoming structures prior to a verb and argue that pre-verbal processing in Japanese is anticipatory and incremental.

\section{L2 Processing}

SLA researchers have been interested in knowing whether or not learners can acquire native-like processing strategies in L2. The findings on this issue are equivocal. While one camp of researchers argue that L2 processing is fundamentally different, especially regarding hidden syntactic features such as gaps (Clahsen \& Felser, 2006), another camp has suggested that proficient L2 speakers can successfully acquire native-like processing strategies that are different from their L1 (Dussias, 2003; Jackson, 2009; Williams, 2006). 
Dussias and Scaltz (2008) have provided supporting evidence that learners keep track of subcategorization biases of L2 verbs. They investigated L1 Spanish advanced ESL learners' use of subcategorization bias information when they read an English sentence like that shown in Sentence (3) and (4), following the adult monolingual study by Garnsey, Pearlmutter, Myers and Lotocky (1997).

(3) The CEO admitted the mistake might have affected the reputation of his company.

(4) The CEO accepted the mistake might have affected the reputation of his company. Garnsey et al. claimed that the likelihood of a verb occurring in a specific syntactic frame guides the initial structural analysis. Namely, Sentence (3) is temporarily ambiguous in that when the comprehenders hit 'the mistake', 'the mistake' can function either as the direct object of 'admitted' or as subject of the sentential complement. However, reading of 'might' should not be disrupted because the verb 'admit' most often takes a sentential complement. On the other hand, in Sentence (4), the comprehenders need reanalysis of 'might', because the verb 'accept' has the direct object bias.

Dussias and Scaltz investigated how L2 learners go about processing this ambiguity. In Spanish, the ambiguities displayed iln (3) and (4) do not arise, because sentential complements are always introduced by the complementizer 'que'. In order to avoid being garden-pathed in English, learners must switch from reliance on detection of the complementizer to reliance on verb-based lexical expectations. In fact, Dussias and Scaltz found that learners were able to demonstrate the same subcategorization bias that was observed by Garnsey, et al. This study shows that learners can shift away from reliance on an overt L1 cue to increase attention to lexically-based expectations. However, we cannot assume that all target structures are equally easy for learner. For example, research by Marinis, Roberts, Felser \& Clahsen (2005) indicates 
that learners can run into serious problems acquiring constructions that are radically different from L1. Specifically, what we do not yet know is whether learners will have difficulty in shifting from verb-driven processing to case marker-driven processing.

The current study asks if L2 learners can switch from a reliance on word order cues to a native-like reliance on case marking cues. As discussed earlier, case marker-driven processing in Japanese requires learners with L1 English to adopt a markedly different method for parsing. However, learners with L1 Korean do not face the same challenge. Korean is also a head-final language with subject-object-verb (SOV) word order as shown in Sentence (5).

(5) Mary-ka John-rul iki-ess-e

Mary-NOM John-ACC hit-PAST-DEC

'Mary hit John'

Case markers for nominative, dative, and accusative serve to encode grammatical roles, and the case system makes it possible for arguments to be scrambled. Sentence (6) shows that the direct object, 'John' scrambles over the subject 'Mary' by keeping the propositional meaning of Sentence (5).

(6) John-rul Mary-ka iki-ess-e John-ACC Mary-NOM hit-PAST-DEC.

'Mary hit John'

From a psycholinguistic perspective, Kim (1999) demonstrated that a Korean parser can incorporate the information posed by case-markers directly into structural building without delay. Given these similarities, it could be that learners with an L1 Korean background would perform case marker-driven processing more easily than those with L1 English background. The cuebased approach of the competition model suggests that learners should be able to successfully 
make this shift regardless of their L1, although the transition may take some time (Kilborn \& Ito, 1989).

\section{Method}

\section{Participants}

Participants included Korean and English learners of Japanese, as well as Japanese native speakers $(N=16$ each). The L2 participants were undergraduate students at Carnegie Mellon University enrolled in either 4th or 6th semester Japanese courses at the time of the experiment. To assess their functional proficiencies in L2, they were asked to complete a self-reported language background questionnaire on several aspects of language proficiency and use. Separate t-tests were performed on the scores from each group on the four areas of Japanese language proficiencies in order to ensure that both groups of L2 learners have enough knowledge to process the target structure under investigation. The information obtained from the questionnaire and the t-test results are shown in Table 1.

\section{TABLE 1 ABOUT HERE}

\section{Materials}

Four types of word-orders: canonical order, dative scrambling, accusative scrambling, and dative-accusative scrambling were tested in the self-pace reading experiment ${ }^{2}$. Examples are given in the following.

(7) a. Canonical order

ofisu-de isogashii shain-ga kibishii shachoo-ni atsui ocha-o dashita

\footnotetext{
${ }^{2}$ Although there are six possible word-orders in the Japanese ditransitive construction, the present study examined four word-order patterns following Yamashita (1997).
} 
office-LOC busy employee-NOM strict president-DAT hot tea-ACC served

'In the office, the busy employee served hot tea to the strict president.'

\section{b. Dative scrambling}

ofisu-de kibishii shachoo-ni isogashii shain-ga atsui ocha-o dashita

c. Accusative scrambling

ofisu-de atsui ocha-o isogashii shain-ga kibishii shachoo-ni dashita

d. Dative-accusative scrambling

ofisu-de kibishii shachoo-ni atsui ocha-o shain-ga isogashii dashita

In (7a) to (7d), there are three NPs (hereafter NP1, NP2, and NP3) followed by a ditransitive verb. In all conditions, NP1 and NP2 were followed by an adjective that modified the following NP. Data from this region was combined in order to take into account any processing spillover effect (e.g., office-LOC / busy / employee-NOM strict / president-DAT hot / tea-ACC served /). NP3 was followed by a verb, but not by an adjective. This difference in the contents of the spillover regions between three NPs should not be problematic, because we conducted a separate statistical analysis for each NP. Verbs were chosen to denote distinct transferring actions such as 'give' and 'serve'. Each sentence had two animate NPs, which function either as the Agent or the Recipient, and one inanimate NP that is transferable. The three NPs were controlled so that one could not construct an interpretation based solely on lexical semantics or world knowledge. For example, sentences such as 'the teacher gives the student homework' were avoided. 
Twelve items were constructed for each word-order type; each participant was given 48 experimental stimuli. A large number of fillers were included ( $48 \%$ of the total trials), and they were similar in length and in complexity. All the vocabularies in the experimental stimuli were taken from a textbook used in the elementary Japanese courses at the university in order to minimize the likelihood of L2 participants' unfamiliarity with vocabulary and subsequent slow down in reading. Also, all the stimuli were written in Hiragana and Katakana script in order to eliminate the possibility of the Korean group having an advantage in character recognition ${ }^{3}$.

\section{Procedure}

Participants performed non-cumulative self-paced reading in a word-by-word moving window display (Just, Carpenter, \& Woolley, 1982). The experiments were conducted with the E-prime program running on a windows computer (Psychological Software Tools, 2000). A stimulus sentence initially appeared as a row of dashes, and participants were instructed to press a button to reveal each subsequent word of the sentence. When participants pressed a button, the first word appeared and replaced the corresponding dashes. But when participants pressed the button again, the first word reverted to dashes, and the second word appeared in place of the corresponding dashes. In this way, each subsequent button-press revealed a new word and removed the preceding word. The time between two button-presses was recorded as the reading time for each word. The sentences were presented in a random order across participants determined by the program. Japanese fonts, MS Mincho 14 point font, were used. Each sentence was followed by a comprehension question in order to avoid participants' pressing buttons blindly. Questions were in a yes-no format and asked to identify the Agent of the action

\footnotetext{
${ }^{3}$ In Korea, the use of Chinese characters was once considered scholarly, and basic Chinese characters are still used, although most forms are written in Hangul (Lee \& Ramsey, 2000).
} 
described. No feedback was given. Only sentences for which participants correctly answered a comprehension question were analyzed further. The data from one native speaker participant was excluded from the analysis, because the comprehension accuracy was below $42 \%$. After the selfpaced reading experiment, L2 participants were asked to complete the paper-pencil grammar test. This test was designed to endure if L2 learners have enough grammar knowledge for the structures under investigation, namely it involved sentence combination task, fill-in-the-gap tasks on case-markers, and other structures with similar structural complexity, such as passives and relative clauses. There were 20 questions and 1 point was given for each correct response. There was no time limit for this grammar test.

\section{Results}

Turning first to the results obtained from the grammar test, an independent samples t-test was conducted on the grammar test scores of the Korean group and the English group. There was no significant difference in the scores of the Korean group and the English group $(M=18.00, S D$ $=2.09 ; M=17.37, S D=2.70$, respectively), $t(30)=-.73, p=.47$. This result indicates that the Korean group and the English group are comparable in their performance on the off-line measure.

Next, we analyzed the self-paced reading time data. Reading times were discarded if they were three standard deviations away from the mean for each word position in each word-order type. Mean reading times were obtained from sentences for which participants correctly answered the comprehension question. Expected reading times were calculated by using a linear regression equation on reading times for each region in each word-order type as a function of the number of characters in it for each participant group. Residual reading times were obtained by subtracting expected reading times for the region of the same length from raw reading times and statistical tests were performed on residual reading times (Ferreira \& Clifton, 1986). Zero 
millisecond is the normalized reading times and words read slower than the normalized reading time have positive reading times.

For the native speaker group, within-subject analyses of variance (ANOVA) were performed on reading times for the three NPs across the four word orders. For the region of NP1, there was no main effect of scrambling type on reading times: $F(3,42)=1.77, p=.16$, partial $\eta^{2}=.11$. For NP2, there was no significant difference on reading times across scrambling type either: $F(3,42)=2.40, p=.08$, partial $\eta^{2}=.14$. Finally, in the last region, NP3, there was again no effect of scrambling type on reading times: $F(3,42)=1.22, p=.31$, partial $\eta^{2}=.08$. The results of the performance of the native speaker group are summarized in Figure 1.

\section{FIGURE 1 ABOUT HERE}

For the English group, the ANOVA revealed that, in the NP1 region, there was no significant main effect of scrambling type on reading times; $F(3,45)=2.57, p=.06$, partial $\eta^{2}=.14$. At the NP2 region, there was no significant difference on reading times across scrambling type either; $F(3,45)=1.22, p=.31$, partial $\eta^{2}=.07$. Finally, in the NP3 region, there was again no effect of scrambling type on reading times; $F(3,45)=1.18, p=.32$, partial $\eta^{2}=.07$. The results from the English group are plotted in Figure 2.

\section{FIGURE 2 ABOUT HERE}

Finally, for the Korean group, there was a significant main effect of scrambling type on reading times in NP1; $F(3,45)=4.23, p<.01$, partial $\eta^{2}=.14$. In order to find the pattern of difference, post hoc pair-wise comparisons were performed with Bonferroni adjustment. Sentences with the dative-accusative order were read more slowly $(M=84.89, S E M=130.29)$ than those with the accusative order $(M=-71.93, S E M=124.94), p=.04$. Other differences were not statistically significant. At NP2, there is no significant difference on reading times across 
scrambling conditions either; $F(3,45)=.79, p=.50$, partial $\eta^{2}=.05$. Finally, in the NP3 region, there is again no effect of scrambling type on reading times; $F(3,45)=.76, p=.37$, partial $\eta^{2}=.02$. The reading time results of the Korean group are shown in Figure 3 .

\section{FIGURE 3 ABOUT HERE}

Overall, the data of the self-paced reading experiments showed that there was no additional processing cost associated with scrambling except for the NP1 region of the Korean group. However, caution has to be made in interpreting such null results. The absence of the scrambling effect could be due to a variety of factors, such as the insensitivity of the measure and inadequate statistical power.

To evaluate the adequacy of finding of no effects, we conducted a further model selection analysis using the Akaike Information Criterion (AIC: Akaike, 1974). Model selection using AIC involves computing log-likelihoods for each potential model. The log-likelihood associated with a model arises from the parameter estimation procedure and models are compared by balancing goodness of fit (Brown \& Prescott, 1999). AIC adjusts for variation in the number of parameters among models by penalizing models with additional parameters. The justification for this procedure is that the model providing the best fit (e.g., the one that accounts for the most variance) is the one that most closely approximates the underlying mental process. Good models have their largest value of log-likelihood and the smallest number of parameters. For data with $n$ observations, we define AIC as: $A I C=-2 \log \lambda-n+2(k-1)$ where $\log \lambda$ is the log-likelihood and $k$ is the number of parameters in the model based on Sakamoto and Akaike $(1978)^{4}$.

\footnotetext{
${ }^{4}$ AIC prefers models with higher complexity than Bayesian Information Criterion (BIC) and leads us to take a conservative approach. For referential purpose, we also performed BIC, and the results are the same as those we obtained via AIC.
} 
Model selection is not the standard repertoire of statistical procedures used in the L2 processing arena; it is sometimes used in cognitive psychology, such as perceptual categorization (e.g., Erickson \& Kruschke, 2001). Our intention here is select one model that best captures the underlying mental process, which in this case is the distribution of reading times of all, collapsing over the independent variable, word-order types.

Four models are constructed with variables regarding means $(\mu)$ and variances $(\varepsilon)$ of the reading time data of four word-order types. Since our reading time data met the normality assumption prior to the ANOVA analysis, it is legitimate to use means and variances to describe the distribution of the observations. The followings are the descriptions of variables that we plugged into log-likelihood calculations. The number of parameters $(k)$ in each model is given in parenthesis.

$$
\begin{array}{lll}
\text { Model 1) } & y_{i}=\mu_{i}+\varepsilon_{i} \quad(k=2) \\
\text { (Model 2) } & y_{i}=\mu_{i}+\varepsilon_{i j} \quad(k=5) \\
\text { (Model 3) } & y_{i j}=\mu_{i j}+\varepsilon_{i} \quad(k=5) \\
\text { (Model 4) } & y_{i j}=\mu_{i j}+\varepsilon_{i j} \quad(k=8)
\end{array}
$$

The underlying claim we advance here is that if the patterns of reading performance are different depending on the word-order types, the distribution is to be captured by models with different means and variances, for instance, either by Model 3 or Model 4. AIC was performed on each region of different participant groups for comparing 4 models defined above. The detailed AIC scores are tabulated in Table 2.

\section{TABLE 2 ABOUT HERE}

For the native speaker data, AIC selected Model 1 for all the regions. This model fits the data using only one mean and one variance, thereby embodying the null hypothesis. For the 
English group, AIC scores were smallest in Model 1 for NP1 and NP2, but Model 2 was selected for NP3. This might be due to the larger standard error identified via the ANOVA, and this might lead AIC to choose Model 2 with the equal mean and different group variances. For the Korean group, and the native speaker group, the best model was Model 1.

\section{Discussion and Conclusion}

Data from Japanese native speakers has shown that scrambling conditions were read as quickly as their canonical counterpart. Thereby, we claim that, for native speakers of Japanese, there is no statistically significant processing cost associated with scrambling, as per previous research (Yamashita, 1997). The observation that scrambled sentences were not associated with increased difficulty in parsing is congruent with the theory of cue-based processing. The information from the surface cues was utilized optimally for local thematic assignments. Consequently, this local and incremental processing mitigates the possible processing cost associated with delayed integration of a sequence of NPs. Also, reading times declined smoothly as each NP was processed, suggesting that the Japanese parser can build up expectations for possible continuations. This process can serve as scaling down the search space for possible upcoming constituents and results in cutting down processing time.

Turning next to the results from the two groups of L2 learners of Japanese, we see that L2 learners of Japanese processed the ditransitive sentences in a native-like manner regardless of their L1 backgrounds. These results bear out the claim that L2 processing is not qualitatively different from that of native speakers and L2 learners are able to acquire native-like processing strategies (e.g., Dussias, 2003). Our findings further extend this argument to the area of casemarker driven incremental processing in Japanese. However, other details emerged in the findings, which we discuss below. 
Mention should first be made of one exceptional region, NP1, in which we observed significantly faster reading times by the Korean group; NP-ACC was read faster than NP-DAT. According to the cue-based processing approach, this can be attributed to the higher cue validity and cue strength of the accusative marker in Japanese. Ito, Tahara, and Park (1993) reported Japanese native speakers' cue reliance hierarchy as: $o(\mathrm{ACC})>g a(\mathrm{NOM})>w a(\mathrm{TOP})$. The accusative case-marker is a highly reliable cue for assigning syntactic object, whereas the nominative marker $g a$ diminishes reliability in its competition with the topic marker, $w a$. Moreover, $g a$ has multiple functions; in the active voice, $g a$ singles the subject role, but on the other hand in the passive voice, NP-NOM refers to the Patient shown in Sentence (8).

(8) John-ga Mary-ni tatakareta John-NOM Mary-DAT hit-PASS-PAST 'John was hit by Mary'

Thus, the accusative preference can be viewed as a result of its high cue reliability (Kempe \& MacWhinney, 1998; 1999 for a related claim on the L2 acquisition of Russian and German) ${ }^{5}$. The native speaker group and the English group also showed slightly faster reading at NP-ACC although the difference was only marginally significant. It remains to be seen why only the Koreans showed this effect clearly.

It is worth mentioning that, despite our prediction on the effect of L1 cue-reliance, both L2 groups performed native-like regardless of the different processing strategies used in their L1s. The finding contrasts with a previous study of Mitsugi, MacWhinney and Shirai (2010) on

\footnotetext{
${ }^{5}$ Another possible source of the observed accusative preference can be semantic restriction of NP-ACC. In ditransitive construction, NP-ACC most likely would be inanimate and transferrable objects. This semantic characteristic of NP-ACC might result in faster thematic assignments by excluding themselves from the competition of the other two animate candidates for Agent and Goal (Carrie Jackson, Personal communication, May 23, 2009)
} 
L2 processing of Japanese relative clauses with the same participant groups. The results showed that the Korean group demonstrated the subject-object asymmetry in processing of Japanese relative clauses like the native speaker group did, but that the English group did not. It is possible that the bi-clausality of relative clauses requires more global level structural processing (Pienemann, 1989), which might trigger some constraint on L2 learners with L1 English background.

Finally, although the AIC analysis lent support to the conclusion that there is no measurable scrambling effect in Japanese, AIC is not a significance test and thus it does not remove the possibility of type II error resulting from the limited number of participants. Furthermore, as pointed out by Miyamoto (2008), it is possible that the self-paced reading method is not sensitive enough to pick up the scrambling effect. In fact, Mazuka, Kondo, and Itoh (2003) found slower reading times on scrambled sentences using eye-tracking methodology. However, that difference was significant only in regard to total reading times and regressive eyemovements, but not in more immediate measures, such as first-pass fixation. Sensitive measures, such as eye-tracking can pick up qualitative differences in response patterns and provide information about subtly different classes of events. Replication is thus warranted with a larger participant group and with possibly more sensitive methodologies in order to place our claim on more secure footing. However, we can already conclude from our current results that the processing of case markers as required for understanding scrambled sentences is not a major barrier for L2 learners of Japanese.

To conclude, the results from the current study suggested that there is no extra processing load associated with ditransitive scrambling in Japanese for native speakers and L2 learners of Japanese with L1 Korean and English backgrounds. Additionally, the pattern of the reading 
performance for Korean learners pointed to for the role of cue reliability in processing L2 case markers. The cue-based processing account interpreted the results such that sentence processing is mediated by an identification of surface cues and that processing gets smoother if the language provides stable cues for immediate integration of thematic assignment. Our results have also illustrated that L2 processing is not fundamentally different from L1 processing at least in the domain of the Japanese ditransitive structure, although there is a variation in terms of the rapidity with which linguistic information is utilized. 


\section{References}

Akaike, H. (1974). A new look at the statistical model identification. IEEE Transactions on Automatic Control 19(6), 716-723.

Bates, E., \& MacWhinney, B. (1982). Functionalist approaches to grammar In E. Wanner \& L. Gleitman (Eds.), Language acquisition: The state of the art (pp. 173-218). New York: Cambridge University Press.

Clahsen, H., \& Felser, C. (2006). Grammatical processing in language learners. Applied Psycholinguistics, 27(1), 3-42.

Dussias, P. E. (2003). Syntactic ambiguity resolution in L2 learners. Studies in Second Language Acquisition, 25(4), 529-557.

Dussias, P. E., \& Scaltz, T. (2008). Spanish-English L2 speakers' use of subcategorization bias information in the resolution of temporary ambiguity during second language reading. Acta Psychologia, 128(3), 501-513.

Edwards, L. (1993) Applied analysis of variance in behavioral science. NY: Marcel Dekker.

Erickson, M., \& Kruschke, J. (2002). Rule-based extrapolation in perceptual categorization. Psychonomic Bulletin \& Review, 9(1), 160-168.

Ferreira, F., \& Clifton, C. (1986). The independence of syntactic processing. Journal of Memory and Language, 25(3), 348-368.

Garnsey, S. M., Pearlmutter, N. J., Myers, E., \& Lotocky, M. A. (1997). The Contributions of verb bias and plausibility to the comprehension of temporarily ambiguous sentences, Journal of Memory and Language 37(1), 58-93. 
Hoji, H. (1987). Weak crossover and Japanese phrase structure. In T. Imai \& M. Saito (Eds.), Issues in Japanese linguistics (pp. 163-201). Dordrecht, Holland.

Ito, T., Tahara, T., \& Park, W. (1989). Japanese particles as case markers: Developmental psycholinguistic comparison between Japanese and Korean, and within Japanese. In F. C. Peng, V. M. Peng, H. Miyake, M. Sasaki \& T. Watanabe (Eds.), Language in the individual and society (pp. 93-111). Hiroshima, Japan: Bunka Hyoron.

Just, M. A., Carpenter, P., \& Woolley, J. D. (1982). Paradigms and processes and in reading comprehension. Journal of Experimental Psychology: General, 111(2), 228-238.

Kamide, Y., Altmann, G. T. M., \& Haywood, S. L. (2003). The time-course of prediction in incremental sentence processing: evidence from anticipatory eye movements. Journal of Memory and Language, 49(1), 133-156.

Kempe, V., \& MacWhinney, B. (1998). The acquisition of case markings by adult learners of Russian and German. Studies in Second Language Acquisition, 20(4), 543-587.

Kempe, V., \& MacWhinney, B. (1999). Processing of morphological and semantic cues in Russian and German. Language and Cognitive Processes, 14(2), 129-171.

Kilborn, K., \& Ito, T. (1989). Sentence processing strategies in adult bilinguals. In B. M. E. Bates (Ed.), The crosslinguistic study of sentence processing (pp. 257-291). New York: Cambridge University Press.

Kim, Y. (1999). The effect of case marking information on Korean sentence processing. Language and Cognitive processes, 14(5/6), 687-714.

Kuno, S. (1973). The structure of the Japanese language. Cambridge, MA: MIT Press.

Lee, I., \& Ramsey, S. R. (2000). The Korean Language. NY: State University of New York Press. 
MacDonald, M., Pearlmutter, N., \& Seidenberg, M. (1994). The lexical nature of syntactic ambiguity resolution. Psychological Review, 101(4), 676-703.

MacWhinney, B. (2008). How mental models encode embodied linguistic perspectives. Mahwah, NJ: Lawrence Erlbaum Associates.

MacWhinney, B., \& Bates, E. (1989). The cross-linguistic study of sentence processing. New York: Cambridge University Press.

Marinis, T., Roberts, L., Felser, C., \& Clahsen, H. (2005). Gaps in second language sentence processing. Studies in Second Language Acquisition 27(1), 53-78.

Mazuka, R., Itoh, K., \& Kondo, T. (2002). Cost of scrambling in Japanese sentence processing. In M. Nakayama (Ed.), Sentence processing in East Asian languages (pp. 131-166). Stanford: CSLI.

Mitsugi, S., MacWhinney, B., \& Shirai, Y. (2010). The cue-based processing of relative clauses in second language Japanese. In M. Prior, \& Y. Watanabe (Eds.), Selected proceedings of the second language research forum 2008, Somerville, MA: Cascadilla Proceedings Project.

Miyamoto, E. (2002). Case markers as clause boundary inducers in Japanese. Journal of Psycholinguistic Research, 31(4), 307-347.

Miyamoto, E. (2008). Processing sentences in Japanese. In S. Miyagawa \& M. Saito (Eds.), The oxford handbook of Japanese linguistics (pp. 217-249): Oxford University Press.

Miyamoto, E., \& Nakamura, M. (2005). Unscrambling some misconceptions: A comment on Koizumi and Tamaoka (2004). Gengo Kenkyu, 128, 113-129. 
Miyamoto, E. T., \& Takahashi, S. (2002). Sources of difficulty in the processing of scrambling in Japanese. In M. Nakayama (Ed.), Sentence processing in East Asian languages (pp. 167-188). Stanford, CA: CSLI.

Nakayama, M. (1995). Scrambing and probe recognition. In R. Mazuka \& N. Nagai (Eds.), Japanese setence processing (pp. 257-273). Hillsdale, NJ.: Lawrence.

Nakayama, M. (1999). Sentence processing. In N. Tsujimura (Ed.), The handbook of Japanese linguistics (pp. 398-424). Malden, MA.: Blackwell Publishing.

Nemoto, N. (1999). Scrambling. In N. Tsujimura (Ed.), The handbook of Japanese linguistics. Oxford, UK: Blackwell.

Papadopoulou, D., \& Clahsen, H. (2006). Ambiguity resolution in sentence processing: The role of lexical and contextual information. Journal of Linguistics, 42(1), 109-138.

Pienemann, M. (1989). Is language teachable? Psycholinguistic experiments and hypotheses. Applied Linguistics, 10(1), 52-79.

Priechett, B. (1992). Grammatical competence and parsing performance. Chicago, IL: University of Chicago Press.

Ross, J. (1967). Constraints on variables in syntax. Doctoral dissertation, Massachusetts Institute of Technology.

Saito, M. (1985). Some asymmetries in Japanese and their theoretical consequence. Doctoral Dissertation, Massachusetts Institute of Technology, Massachusetts, MA.

Sakamoto, Y., \& Akaike, H. (1978). Analysis of cross classified data by AIC. Annals of the Institute of Statistical Mathematics, 30(1), 185-197. 
Trueswell, J. C., Tanenhaus, M. K., \& Kello, C. (1993). Verb-specific constraints in sentence processing: Separating effects of lexical preference from garden-paths. Experimental Psychology: Learning, Memory, \& Cognition, 19(3), 528-553.

Williams, J. N. (2006). Incremental interpretation in second language sentence processing. Bilingualism: Language and Cognition, 9(1), 71-88.

Yamashita, H. (1997). The effects of word order and case marking information on the processing of Japanese. Journal of Psycholinguistic Research, 26(2), 163-188.

Yamashita, H. (2002). Scrambled sentences in Japanese: Linguistic properties and motivations for production. Text, 22(4), 597-633 
Table 1

The Self-rated Proficiency and Learning Background

\begin{tabular}{lllll}
\hline & \multicolumn{2}{l}{ L1 background } & & \\
\cline { 2 - 5 } Measure & English & Korean & $t$ & $p$ \\
\hline Age (years) & $20.00(1.26)$ & $21.37(2.44)$ & - & - \\
Time studied Japanese (years) & $3.28(3.27)$ & $2.78(1.25)$ & - & - \\
Immersion experience (years) & $0.00(0.00)$ & $0.62(1.74)$ & - & - \\
Listening ability & $5.34(2.27)$ & $5.75(1.98)$ & .414 & .682 \\
Speaking ability & $4.93(2.14)$ & $4.87(2.09)$ & .083 & .932 \\
Reading ability & $5.31(1.88)$ & $5.18(1.55)$ & .204 & .84 \\
Writing ability & $5.00(1.46)$ & $4.75(1.25)$ & .522 & .605
\end{tabular}

Note. Standard deviations are given in parentheses. Reading, writing, listening and speaking ability were rated on a 10-point scale where 1 indicates the lowest and 10 indicates the highest level of ability. 
Table 2

AIC Values for Models for the Reading Rime Data

\begin{tabular}{lllllc}
\hline Groups & Regions & Model 1 & Model 2 & Model 3 & Model 4 \\
\hline Native speaker & NP1 & $851.98^{*}$ & 857.05 & 857.27 & 862.39 \\
& NP2 & $813.55^{*}$ & 817.51 & 818.12 & 822.22 \\
& NP3 & $769.79 *$ & 773.44 & 771.93 & 775.89 \\
\hline L1 English & NP1 & $960.82^{*}$ & 964.71 & 965.22 & 968.76 \\
& NP2 & $974.25^{*}$ & 979.78 & 979.53 & 985.08 \\
& NP3 & 1012.96 & $980.77 *$ & 1015.83 & 983.11 \\
\hline L1 Korean & NP1 & $983.48^{*}$ & 989.04 & 988.35 & 993.89 \\
& NP2 & $963.33^{*}$ & 968.67 & 968.96 & 974.3 \\
& NP3 & $944.92^{*}$ & 949.05 & 950.75 & 954.86 \\
\hline
\end{tabular}

Note. Asterisks indicate the smallest AIC scores. 


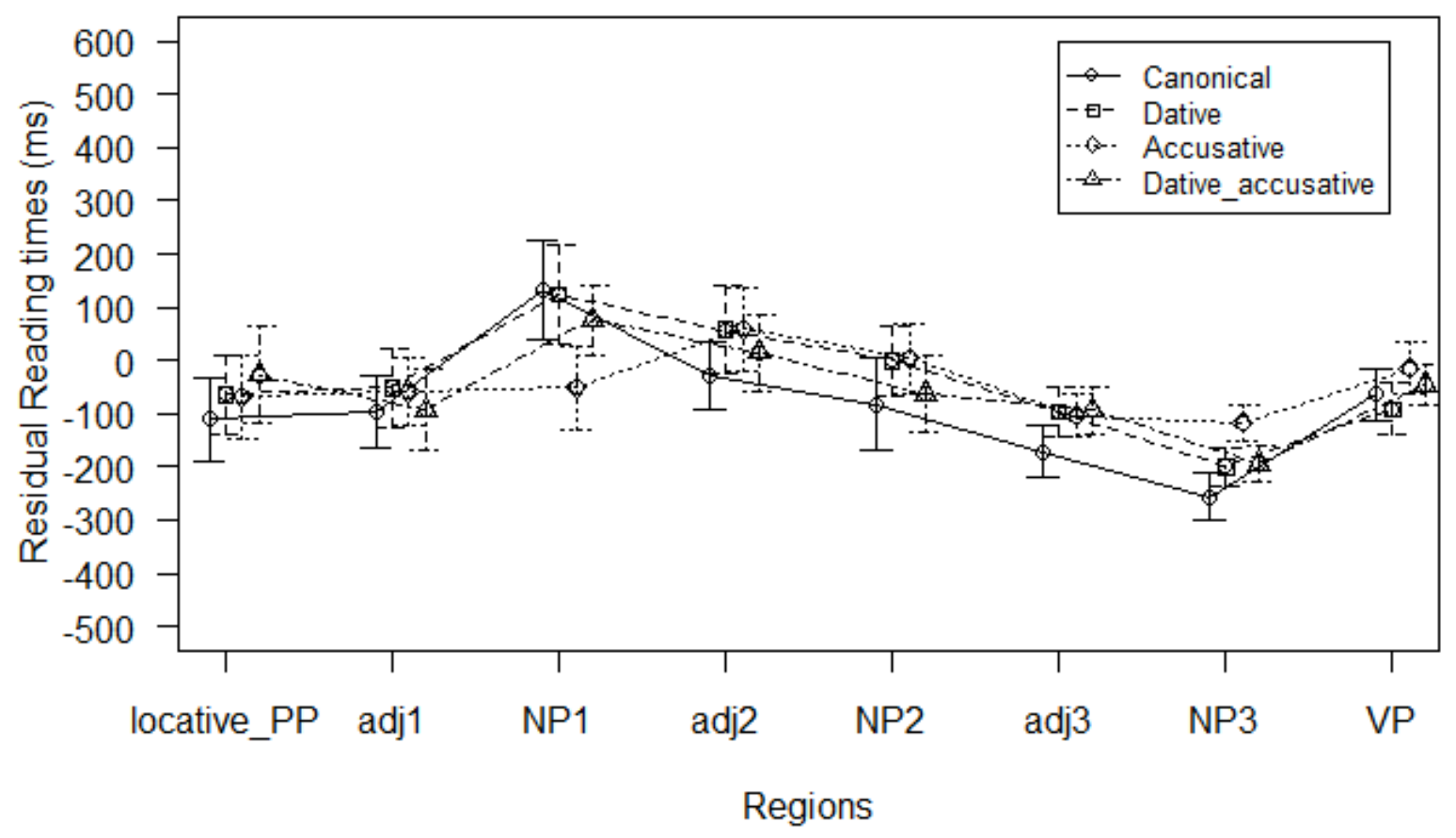

Figure 1. The processing performance of the native speaker group 


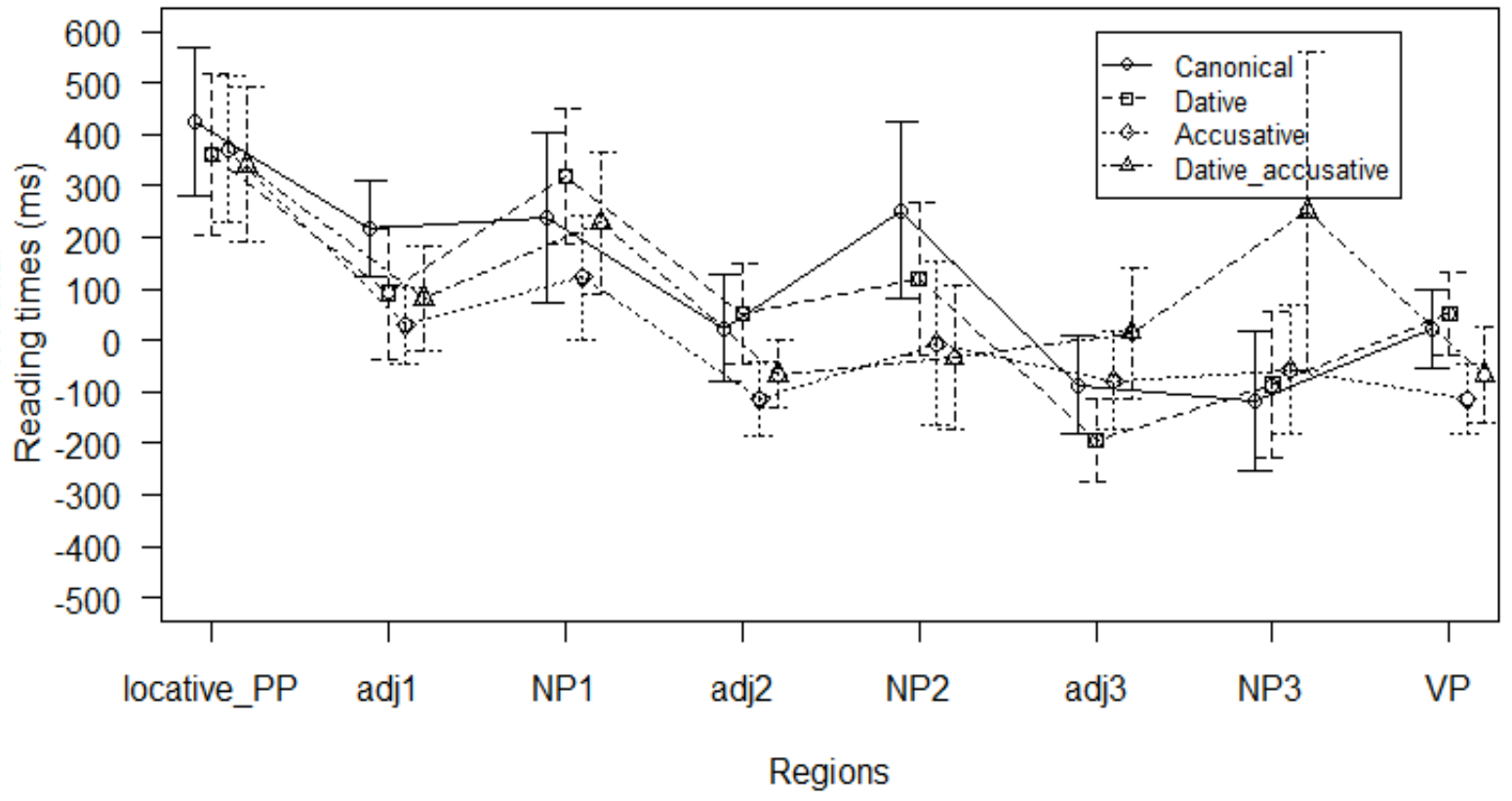

Figure 2. The processing performance of the English group. 


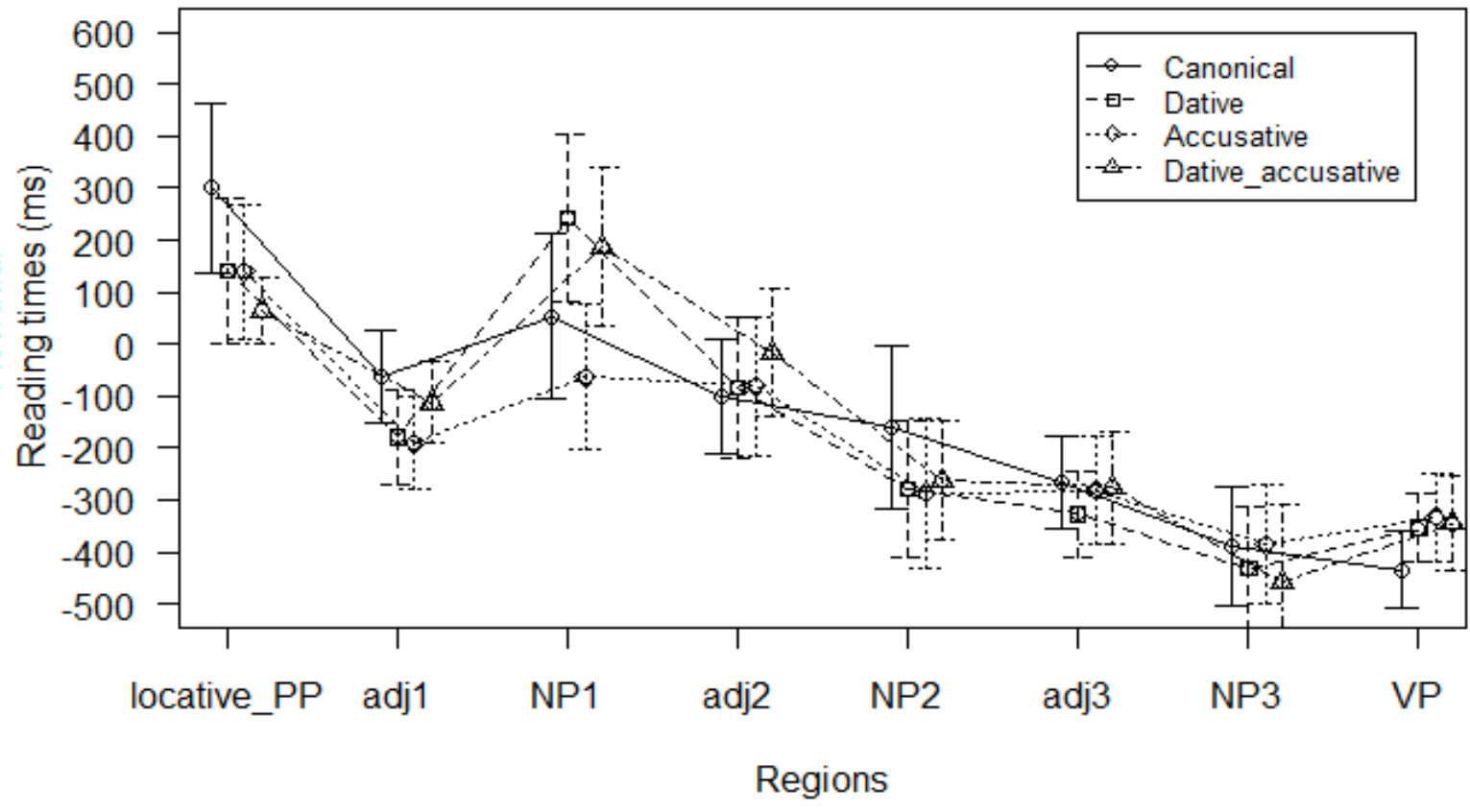

Figure 3. The processing performance of the Korean group. 